Jurnal Indonesia Sosial Teknologi:p-ISSN: 2723 - 6609

e-ISSN :2745-5254

Vol. 2, No.12 Desember 2021

\title{
PENERAPAN CONSTRACTOR SAFETY MANAGEMENT SYSTEM (CSMS) DAN DASAR HUKUMNYA DI PT. PERTAMINA REFINERY UNIT VI BALONGAN
}

\author{
Yenny Frisca Madhona ${ }^{1}$, Andi Lala ${ }^{2}$. \\ Akamigas Balongan ${ }^{1,2}$ \\ Email: yennyfriscamadhona@yahoo.com ${ }^{1}$, andidoshukum@gmail.com ${ }^{2}$
}

\begin{abstract}
Abstrak
Contractor Safety Management System (CSMS) adalah sebuah sistem yang dikelola untuk memastikan bahwa kontraktor yang bermitra dengan PT.Pertamina Refinery Unit VI Balongan telah memiliki manajemen HSE dan telah memenuhi persyaratan HSE yang berlaku di PT.Pertamina Refinery Unit VI Balongan serta mampu menerapkan persyaratan HSE dalam pekerjaan kontrak yang dilaksanakan. Penelitian ini bertujuan untuk menggambarkan perusahaan PT.Pertamina Refinery Unit VI Balongan sebagai perusahaan kilang minyak terbesar dalam hasil produksinya. Kemudian bagaimana penerapan Contractor Safety Management System (CSMS) PT.Pertamina Refinery Unit VI Balongan serta bagaimana dasar hukumnya dalam penerapan Contractor Safety Management System (CSMS) PT.Pertamina Refinery Unit VI Balongan. Metode yang digunakan dalam penelitian ini, penulis menggunakan metode deskriptif-kualitatif dengan mengkaitkan antara data primer yang didapat dari hasil wawancara langsung dengan responden dan data skunder yang di olah dari jurnal,buku serta peraturan perundang-undangan. Hasil penelitian itu sendiri, maka penulis dapat menyimpulkan bahwa mengimplementasikan Contractor Safety Management System (CSMS). Penerapan Contractor Safety Management System oleh PT.Pertamina Refinery Unit VI Balongan sangat penting, karena ini merupakan bagian dari manajemen keselamatan dan kesehatan kerja. Penerapan CSMS oleh PT.Pertamina Refinery Unit VI Balongan mengacu pada pedoman CSMS No.A-001/K00100/2015-S9 Revisi Ke-03, Surat Keputusan Direksi No.Kpts-051/ C00000/2010-S0 Rev. 02 Tentang Sistem dan Tata Kerja Pengadaan Barang/Jasa, kemudian Permenaker Nomor 5 Tahun 1996 Tentang Perencanaan SMK3 serta Peraturan Pemerintah Nomor 50 Tahun 2012 Penerapan Sistem Manajemen Keselamatan dan Kesehatan Kerja sebagai dasar hukum yang wajib di laksanakan.
\end{abstract}

Kata kunci: Dasar Hukum; Penerapan CSMS; Pertamina Balongan.

\section{Abstract}

The Contractor Safety Management System (CSMS) is a system that is managed to ensure that contractors who partner with PT. Pertamina Refinery Unit VI Balongan have HSE management and have met the HSE requirements that apply at PT. Pertamina Refinery Unit VI Balongan and are able to implement HSE requirements in contract work. This study aims to describe the company PT.Pertamina Refinery Unit VI Balongan as the largest oil refinery company in its production. Then how is 
the implementation of the Contractor Safety Management System (CSMS) of PT. Pertamina Refinery Unit VI Balongan and what is the legal basis for implementing the Contractor Safety Management System (CSMS) of PT. Pertamina Refinery Unit VI Balongan. The method used in this study, the author uses a descriptive-qualitative method by linking primary data obtained from direct interviews with respondents and secondary data processed from journals, books and legislation. The results of the research itself, the authors can conclude that implementing the Contractor Safety Management System (CSMS). The implementation of the Contractor Safety Management System by PT. Pertamina Refinery Unit VI Balongan is very important, because it is part of occupational safety and health management. The implementation of CSMS by PT.Pertamina Refinery Unit VI Balongan refers to the CSMS guideline No.A-001/K00100/2015-S9 3rd Revision, Decree of the Board of Directors No.Kpts051/C00000/2010-SO Rev. 02 concerning the System and Work Procedure for the Procurement of Goods/Services, then the Minister of Manpower Regulation Number 5 of 1996 concerning the Planning of SMK3 and Government Regulation Number 50 of 2012 The application of the Occupational Health and Safety Management System as a legal basis that must be implemented.

Keywords: Legal Basis, Application of CSMS, Pertamina Balongan

\section{Pendahuluan}

Perkembangan dan pertumbuhan suatu negara baik sekarang maupun dimasa yang akan datang tentunya tidak bisa lepas dari peranan proses industrialisasi (A'yun, 2020). Untuk dapat membangun tenaga kerja yang produktif, sehat dan berkualitas perlu adanya manajemen yang baik terutama yang terkait dengan masalah Keselamatan dan Kesehatan Kerja (K3) (Yuliani, Ekawati, \& Kurniawan, 2015) Setiap tempat kerja mempunyai risiko terjadinya kecelakaan. Kecelakaan akibat kerja adalah kecelakaan yang terjadi dikarenakan oleh pekerjaan atau pada waktu melaksanakan pekerjaan pada perusahaan. Secara garis besar kejadian kecelakaan kerja disebabkan oleh dua faktor, yaitu tindakan manusia yang tidak memenuhi keselamatan kerja (unsafe act) dan keadaan-keadaan lingkungan yang tidak aman (unsafe condition) (Suma'mur, 1981).

Menurut Keputusan Menteri Tenaga Kerja dan Transmigrasi Republik Indonesia No : KEP.248/MEN/V/2007 saat ini perkembangan industri minyak dan gas sangat besar di Indonesia. Kegiatan industri migas mulai produksi, pengolahan maupun transportasi mempunyai potensi bahaya yang sangat besar yaitu terjadinya kecelakaan kerja dan kebakaran (Mardiah, 2017). Secara global, ILO memperkirakan sekitar 337 juta kecelakaan kerja terjadi tiap tahunnya yang mengakibatkan sekitar 2,3 juta pekerja kehilangan nyawa. Sementara itu data PT Jaminan Sosial Tenaga Kerja (Jamsostek) memperlihatkan bahwa sekitar 0,7 persen pekerja Indonesia mengalami kecelakaan kerja yang mengakibatkan kerugian nasional mencapai Rp 50 triliun (ILO, 2011). Menurut data Jamsostek terdapat 103.000 kasus kecelakaan kerja pada tahun 2012 dan setiap hari ada 9 pekerja yang meninggal dunia akibat kecelakaan kerja pada tahun yang sama (Suryanto, 2013). 
PT.Pertamina (Persero) sebagai perusahaan yang bergerak dalam industri energi nasional selalu dihadapkan kepada potensi resiko bahaya dalam pelaksanaan pekerjaan seperti kebakaran, ledakan, kecelakaan kerja, penyakit akibat kerja dan pencemaran lingkungan. Hal ini mengharuskan Pertamina mengelola aspek health, safety dan environment (HSE) semaksimal mungkin untuk mewujudkan operasi yang aman, andal dan efesiensi. Beberapa potensi bahaya diantaranya terbakar, tersengat listri, meledak, terpapar radiasi, terpapar zat kimia, terjatuh, terjepit dan tertimpa (Mardiah, 2017).

PT. Pertamina Refinery Unit VI Balongan sebagai perusahaan yang bergerk dalam industri energi nasional selalu dihadapkan kepada potensi risiko bahaya dalam pelaksanaan pekerjaannya seperti kebakaran, ledakan, kecelakaan kerja, penyakit akibat kerja dan pencemaran lingkungan. Hal ini mengharuskan perusahaan mengelola aspek health, safety \& environment (HSE) semaksimal mungkin untuk mewujudkan operasi yang aman, andal dan efisien guna mendukung visi dan misi perusahaan. Penerapan aspek health, safety, and environment (HSE) di lingkungan PT. Pertamina Refinery Unit VI Balongan telah diimplementasikan dalam rantai pasokan dengan cara memberlakukan Contractor Safety Management System (CSMS) kepada pemasok, calon pemasok, maupun mitra dan calon mitra kerja penyedia barang / jasa. Contractor Safety Management System merupakan sistem yang dikelola untuk memastikan bahwa kontraktor yang akan bermitra dengan Pertamina Refinery Unit VI Balongan telah memiliki sistem manajemen HSE dan telah memenuhi persyaratan HSE yang berlaku di Pertamina Refinery Unit VI Balongan serta mampu menerapkan persyaratan HSE dalam pekerjaan kontrak yang dilaksanakan (Nugroho, 2011).

Implementasi CSMS di PT Pertamina Refinery Unit VI Balongan mengacu pada Pedoman CSMS No.A-001/K00100/2015-S9 Revisi Ke-03. Pengadaan barang dan jasa di lingkungan PT Pertamina Refinery Unit VI Balongan mengacu kepada Surat Keputusan Direksi No.Kpts-051/ C00000/2010-S0 Rev. 02 tentang Sistem dan Tata Kerja Pengadaan Barang/Jasa (tidak menyebutkan ketentuan khusus terkait pemberdayaan vendor lokal). Fungsi Procurement mengoordinasi kebutuhan pengadaan barang dan jasa yang diatur dalam sistem pengadaan, sehingga barang dan jasa dapat dipenuhi tepat waktu (Ramli, 2013).

\section{Metode Penelitian}

Jenis penelitian yang digunakan dalam penelitian ini bersifat deskriptif-kualitatif, (Moleong, 2009) menggunakan data primer yang diperoleh dari para pihak yang terkait dengan CSMS yaitu kontraktor dan pemangku kepentingan di PT Pertamina Refinery Unit VI Balongan serta data sekunder berupa rekam data safety di departemen EHS PT Pertamina Refinery Unit VI Balongan. Data yang diperoleh dan dikumpulkan dalam penelitian ini bersumber dari data primer dan data sekunder. Data primer diperoleh dari hasil wawancara mendalam (indepth interview) dengan pihak-pihak yang berhubungan dengan pengelolaan CSMS di PT Pertamina Refinery Unit VI Balongan. Wawancara mendalam dengan menggunakan pertanyaan terbuka dan menggali jawaban secara 
mendalam. Informan dalam penelitian ini adalah manajer K3LL, staf K3LL, personel yang menangani proses CSMS. Sementara untuk dara sekunder sendiri penulis ambil dari beberapa jurnal, buku dan aturan perundang-undangan. Kemudian penulis menganalisis data hasil penelitian tentang pelaksanaan implementasi tahapan CSMS yang ada di PT Pertamina Refinery Unit VI Balongan.

\section{Hasil dan Pembahasan}

\section{Gambaran Umum PT. Pertamina Refinery Unit VI Balongan}

PT. Pertamina Refinery Unit VI Balongan adalah salah satu unit operasi Kilang PT Pertamina yang mengolah minyak dan gas bumi menjadi produk BBM (Bahan Bakar Minyak), Non BBM, dan Petrokimia. PT Pertamina Refinery Unit VI Balongan memiliki dua lokasi Kilang, yaitu Kilang Balongan dan Kilang Produksi LPG Mundu (LPM) dengan wilayah operasi di Balongan, Mundu, dan Salam Darma. PT Pertamina Refinery Unit VI Balongan dibangun sejak tahun 1990 dan mulai beroperasi tahun 1994 sampai dengan sekarang. Bahan baku yang diolah oleh Kilang PT Pertamina Refinery Unit VI Balongan adalah minyak mentah (Crude Oil) Duri dan Minas yang berasal dari Propinsi Riau. Keberadaan PT Pertamina Refinery Unit VI Balongan sangat strategis bagi bisnis PT Pertamina maupun bagi kepentingan nasional. Beberapa peranan dan keunggulan PT Pertamina Refinery Unit VI Balongan diantaranya :

a. Sebagai Kilang yang Strategis :

1. Pemasok utama kebutuhan Premium untuk DKI.

2. Pemasok utama LPG di DKI dan Jabar.

3. Memproduksi 95\% dari total produksi Pertamax.

4. Memproduksi $100 \%$ total produksi Pertamax Plus.

5. Memasok Minyak Tanah serta Solar bagi DKI/Jabar.

6. Sebagai alternatif untuk pintu masuk pasokan BBM ke DKI

b. Sebagai Kilang Unggulan :

1. Konfigurasi Kilang dirancang tidak memproduksi residue.

2. Unit proses terintegrasi secara penuh.

3. Terintegrasi dengan sistem distribusi/UPMS melalui pipanisasi.

4. Menghasilkan produk petrokimia yang mempunyai added value diantaranya : Propylene dengan kualitas diatas komersial grade.

5. Menghasilkan produk BBM yang ramah lingkungan.

Sementara itu Visi dan Misi dari PT Pertamina Refinery Unit VI Balongan adalah sebagai berikut ;

1) Visi PT Petamina (Persero) Refinery Unit VI Balongan Menjadi kilang terkemuka di Asia tahun 2025

2) Misi PT Pertamina Refinery Unit VI Balongan 
a. Mengolah crude dan naptha untuk memproduksi BBM, BBK, Residu, NBBM dan Petkim secara tepat jumlah, mutu, waktu, dan berorientasi laba serta berdaya saing tinggi untuk memenuhi kebutuhan pasar.

b. Mengoperasikan kilang yang berteknologi maju dan terpadu secara aman, handal, efisien dan berwawasan lingkungan.

c. Mengelola asset RU - VI secara profesional yang didukung oleh sistem manajemen yang tangguh berdasarkan semangat kebersamaan, keterbukaan, dan prinsip saling menguntungkan.

\section{Penerapan Contractor Safety Management System (CSMS) di PT. Pertamina Refinery Unit VI Balongan}

Contractor Safety Management System (CSMS) adalah suatu pengembangan dari sistem dan mekanisme K3 sebelumnya di PT.Pertamina Refinery Unit VI Balongan untuk meyakinkan pengelolaan K3 yang terstandarisasi bagi para kontraktor di area operasi PT.Pertamina Refinery Unit VI Balongan fasilitas, dan areaarea lain yang menjadi tanggung jawab PT.Pertamina Refinery Unit VI Balongan (Pedoman CSMS No. A001/K00100/2015-S9 Revisi Ke-3).

Contractor Safety Management System CSMS bertujuan mencegah dan mengurangi kecelakaan kerja kontraktor, serta menciptakan tempat kerja yang aman, efisien dan produktif sesuai target yang diberikan oleh PT Pertamina Refinery Unit VI Balongan. Kontraktor dengan pengawasan diri sendiri (self supervised) adalah merupakan sasaran dari program CSMS ini, yaitu kontraktor yang bekerja di area kerja PT Pertamina RU VI Balongan yang dengan organisasi dan manajemennya sendiri mengawasi pelaksanaan pekerjaan dan K3nya.

Untuk mempermudah memahami tahapan dan prosedur Contractor Safety Management System (CSMS) yang diatur dalam pedoman ini, maka disusunlah siklus CSMS yang berlaku di PT Pertamina Refinery Unit VI Balongan sebagai berikut:

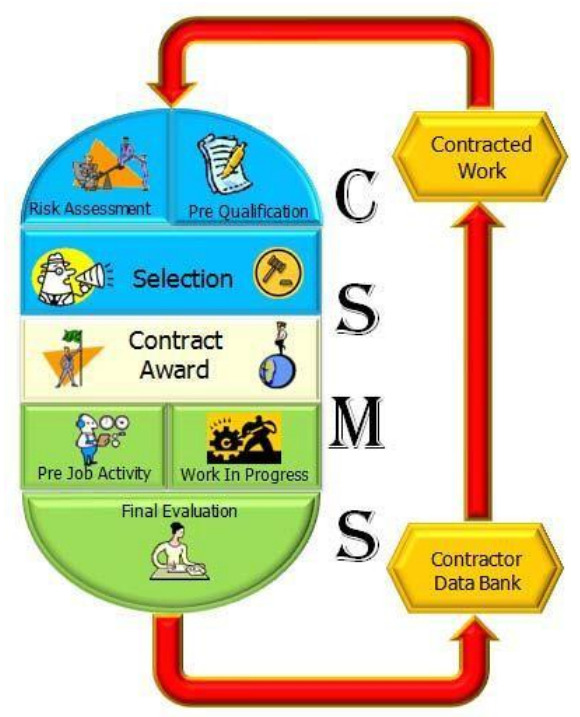


Gambar..1 Silkus CSMS

Untuk menjelaskan siklus tersebut, secara detail tahapan penerapan Contractor Safety Management System dapat dijelaskan dengan flowchart sebagai berikut:

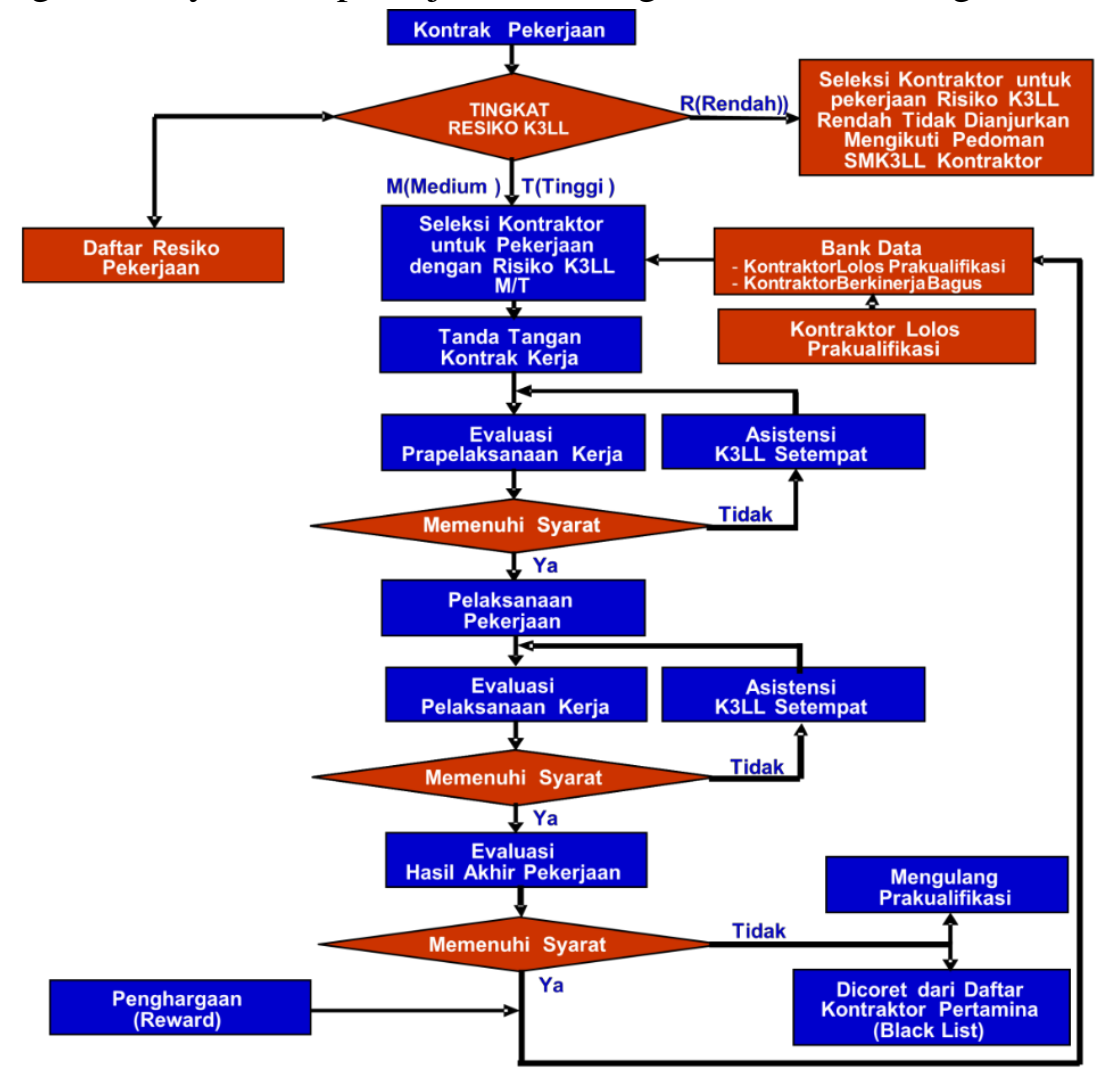

Gambar 2.Tahapan Prosedur CSMS PT Pertamina Refinery Unit VI Balongan

PT Pertamina Refinery Unit VI Balongan sebagai perusahaan yang bergerk dalam industri energi nasional selalu dihadapkan kepada potensi risiko bahaya dalam pelaksanaan pekerjaannya seperti kebakaran, ledakan, kecelakaan kerja, penyakit akibat kerja dan pencemaran lingkungan. Hal ini mengharuskan perusahaan mengelola aspek health, safety \& environment (HSE) semaksimal mungkin untuk mewujudkan operasi yang aman, andal dan efisien guna mendukung visi dan misi perusahaan. Hingga akhir tahun 2017, PT Pertamina Refinery Unit VI Balongan mempekerjakan total 1.830 orang. Para pekerja terdiri dari 1.018 pekerja waktu tidak tertentu (PWTT), 48 pekerja waktu tertentu (PWT), dan 764 outsourching yang terdiri dari tenaga kerja shift dan nonshift.

Pengelolaan aspek HSE tersebut dilaksanakan dengan cara menekan serendah mungkin atau bahkan meniadakan insiden melalui peningkatan pengetahuan, pemahaman dan kesadaran serta kepedulian terhadap aspek HSE kepada semua pihak terkait, baik yang terlibat langsung maupun tidak langsung dalam operasi termasuk para kontraktor.

PT Pertamina Refinery Unit VI Balongan terus melakukan pengembangan, perbaikan dan modifikasi terhadap pabrik dan sarana pendukungnya dengan menunjuk perusahaan kontraktor/subkontraktor sebagai pelaksana pekerjaan. Intensitas proyek dan paket pekerjaan yang tinggi tersebut menyebabkan banyaknya kontraktor dan 
subkontraktor bekerja di dalam area PT Pertamina Refinery Unit VI Balongan. Kontraktor sebagai mitra kerja harus mendapatkan perhatian serius karena kinerjanya dapat mempengaruhi kinerja PT Pertamina Refinery Unit VI Balongan dengan baik yang berdampak terhadap HSE, produktivitas dan citra PT Pertamina Refinery Unit VI Balongan, sehingga PT Pertamina Refinery Unit VI Balongan menerapkan Contractor Safety Management System (CSMS) sebagai persyaratan dalam setiap pengadaa barang/jasa dan harus dipenuhi oleh kontrakor yang menjadi mitra kerja PT Pertamina Refinery Unit VI Balongan yang akan melaksanakan pekerjaan pengadaan barang/jasa tersebut. Berdasarkan data yang di peroleh dari bagian project safety management di HSE PT Pertamina Refinery Unit VI Balongan diketahui total jumlah kontraktor yang terdaftar di PT Pertamina Refinery Unit VI Balongan sebanyak 171 kontraktor dengan katagori high sebanyak 153 kontraktor, medium sebanyak 13 kontraktor dan low sebanyak 5 kontraktor.

Penerapan aspek health, safety, and environment (HSE) di lingkungan PT Pertamina Refinery Unit VI Balongan telah diimplementasikan dalam rantai pasokan dengan cara memberlakukan Contractor Safety Management System (CSMS) kepada pemasok, calon pemasok, maupun mitra dan calon mitra kerja penyedia barang / jasa. Contractor Safety Management System merupakan sistem yang dikelola untuk memastikan bahwa kontraktor yang akan bermitra dengan Pertamina Refinery Unit VI Balongan telah memiliki sistem manajemen HSE dan telah memenuhi persyaratan HSE yang berlaku di Pertamina Refinery Unit VI Balongan serta mampu menerapkan persyaratan HSE dalam pekerjaan kontrak yang dilaksanakan.

Implementasi CSMS di PT.Pertamina Refinery Unit VI Balongan mengacu pada Pedoman CSMS No.A-001/K00100/2015-S9 Revisi Ke-03. Pengadaan barang dan jasa di lingkungan PT Pertamina Refinery Unit VI Balongan mengacu kepada Surat Keputusan Direksi No.Kpts-051/ C00000/2010-S0 Rev. 02 tentang Sistem dan Tata Kerja Pengadaan Barang / Jasa (tidak menyebutkan ketentuan khusus terkait pemberdayaan vendor lokal). Fungsi Procurement mengoordinasi kebutuhan pengadaan barang dan jasa yang diatur dalam sistem pengadaan, sehingga barang dan jasa dapat dipenuhi tepat waktu. Contractor Safety Management System (CSMS) dilaksanakan sebagai salah satu pemenuhan Peraturan Pemerintah RI No. 50 Tahun 2012 mengenai Sistem Manajemen Keselamatan dan Kesehatan Kerja (SMK3) pasal 6 elemen C mengenai Pelaksanaan Rencana K3 disebutkan bahwa kegiatan dalam pelaksanaan rencana K3 paling sedikit meliputi Tindakan Pengendalian, Perancangan \& Rekayasa, Prosedur dan Instruksi Kerja, Penyerahan sebagian pelaksanaan Pekerjaan, Pembelian/Pengadaan barang dan Jasa.

Salah satu unsur dalam sistem manajemen K3 adalah proses manajemen yang digunakan untuk mengelola sistem manajemen yang biasa dikenal dengan siklus Plan-Do-CheckAction yang merupakan proses perencanaan, penerapan, pengukuran, dan Pengelolaan kontraktor melalui Contractor Safety Management System (CSMS) menjadi jembatan antara Occupational Health and Safety Management System perusahaan dan kontraktor yang berfungsi sebagai alat untuk menjaga dan meningkatkan kinerja keselamatan 
lingkungan kontraktor. Fungsi lain CSMS yaitu untuk mencegah dan menghindarkan kerugian yang timbul akibat aktivitas kontraktor (Ramli, 2008). Kontraktor maupun subkontraktor dituntut untuk melaksanakan pekerjaan secara aman dari segi kesehatan dan keselamatan kerja. Maka dalam hal ini, setiap kontraktor maupun subkontrakor yang menjalin kerjasama dengan setiap mitra kerjanya harus mendapatkan perhatian serius, karena kinerjanya dapat mempengaruhi kinerja perusahaan baik yang berdampak pada HSE, produktifitas dan citra suatu perusahaan.

\section{Dasar Hukum Penerapan Contractor Safety Management System (CSMS) di PT. Pertamina Refinery Unit VI Balongan}

Contractor Safety Management System adalah sistem yang dikelola untuk memastikan bahwa kontraktor yang bermitra dengan PT.Pertamina Refinery Unit VI Balongan telah memiliki sistem manajemen HSE dan telah memenuhi persyaratan HSE yang berlaku di PT.Pertamina Refinery Unit VI Balongan serta mampu menerapkan persyaratan HSE dalam pekerjaan kontrak yang dilaksanakan. Pedoman Contractor Safety Management System digunakan sebagai :

a. Acuan bagi seluruh Unit Operasi PT.Pertamina Refinery Unit VI Balongan dalam mengelola aspek HSE untuk pengadaan barang/jasa yang dikontrakkan kepada mitra kerja PT Pertamina (Persero).

b. Acuan atau referensi bagi Anak Perusahaan PT.Pertamina Refinery Unit VI Balongan (termasuk mitra operasi : Joint Operating Body (JOB), Technical Assistence Contract (TAC), Kontrak Operasi Bersama (KOB) dalam menyeleksi para kontraktornya, kecuali jika Anak Perusahaan PT.Pertamina Refinery Unit VI Balongan tersebut sudah mempunyai aturan tersendiri yang lebih ketat dalam pengelolaan aspek HSE terhadap kontraktor yang menjadi mitra kerjanya.

Adapun tujuan PT.Pertamina Refinery Unit VI Balongan mengembangkan Pedoman Contractor Safety Management System (CSMS) adalah sebagai berikut :

a. Memberikan panduan dan penyeragaman kepada seluruh Unit Operasi \& Anak Perusahaan PT.Pertamina Refinery Unit VI Balongan dalam menyeleksi dan mengelola kinerja HSE kontraktor.

b. Memastikan kegiatan operasi PT.Pertamina Refinery Unit VI Balongan berjalan dengan aman untuk mencapai target produksi yang ditetapkan.

c. Meningkatkan produktivitas dan citra positif PT.Pertamina Refinery Unit VI Balongan di mata pelanggan, masyarakat dan semua pihak terkait.

d. Meningkatkan kemampuan mitra kerja PT.Pertamina Refinery Unit VI Balongan terutama kontraktor lokal dalam menghadapi persaingan global.

e. Mengurangi/menghilangkan dampak negatif terhadap aspek HSE untuk mencegah kerugian perusahaan.

f. Meningkatkan kepedulian dan kesadaran kontraktor dalam pengelolaan aspek HSE, sehingga insiden yang disebabkan kontraktor dapat dihilangkan. 
g. Merupakan alat untuk mengontrol konsistensi para kontraktor dalam menerapkan aspek HSE.

Sebagaimana yang terdapat di dalam tujuan penerapan Contractor Safety Management System, maka untuk memenuhi standar manajemen keselamatan kerja dalam pelaksanaan dilokasi pekerjaan, harus sesuai dengan standar atau regulasi yang menjadi acuan atau dasar hukumnya. Peraturan Menteri Tenaga Kerja Nomor Per05/Men/1996 Tentang Sistem Manajemen Keselamatan dan Kesehatan Kerja menjadi salah satu dasar hukum dalam pelaksanaan dan penerapan Contractor Safety Management System (CSMS) di PT. Pertamina Refinery Unit VI Balongan. Tentunya implementasi (CSMS) tersebut diharapkan agar semua tenaga kerja aman dan terselamatkan dari kecelakaan kerja.

Dalam penjelasan aturan tersebut yang terdapat dalam lampiran I dari Permenaker No.5/1996 yang bersi pedoman penerapan SMK3 di Indonesia. Penjelasan-penjelasan berikut dapat dijadikan dasar hukum pentingnya memperhatikan aspek keselamatan dan kesehatan kerja konstraktor di suatu perusahaan. Bab keduan pedoman SMK3 Permenaker No.5/1996 yaitu tentang "perencanaan SMK3" diesbutkan dalam poin Perencanaan Identifikasi Bahaya, Penilaian dan Pengendalian Resiko bahwa "Identifikasi bahaya, penilaian, dan pengendalian risiko dari kegiatan, produk barang dan jasa harus dipertimbangkan pada saat merumuskan rencana untuk memenuhi kebijakan keselamatan dan kesehatan kerja. Untuk itu harus ditetapkan pemeliharaan prosedurnya."

Bab ketiga tentang penerapan "SMK3" dalam poin tinjauan ulang kontrak disebutkan bahwa "Pengadaan barang dan jasa melalui kontrak harus ditinjau ulang untuk menjamim kemampuan perusahaan dalam memenuhi persyaratan keselamatan dan kesehatan kerja yang ditentukan."

Bab "penerapan" yaitu dalam poin pembelian, ada dua pokok yang dibahas yaitu : (a). Sistem pembelian barang dan jasa termasuk didalamnya prosedur pemeliharaan barang dan jasa harus terintegrasi dalam strategi penanganan pencegahan risiko kecelakaan dan penyakit akibat kerja. Sistem pembelian harus menjamin agar produk barang dan jasa serta mitra kerja perusahaan memenuhi persayaratan keselamatan dan kesehatan kerja. (b). Pada saat barang dan jasa diterima d itempat kerja, perusahaan harus menjelaskan kepada semua pihak yang akan menggunakan barang dan jasa tersebut mengenai identifikasi, penilaian dan pengendalian risiko kecelakaan dan penyakit akibat kerja (Falenshina, 2012).

Disamping aturan hukum diatas, ada beberapa aturan hukum yang dapat dijadikan rujukan dalam penerapan Contractor Safety Management System (CSMS) di PT. Pertamina Refinery Unit VI Balongan, antara lain sebagai berikut;

1. UU No.1 Tahun 1970 tentang Keselamatan kerja

2. UU No.4 tahun 1982 tentang Ketentuan-ketentuan pokok pengolahan lingkungan hidup. 
3. Keputusan Presiden Republik Indonesia No. 18 Tahun 2000 Tentang Pedoman Pelaksanaan Pengadaan Barang/Jasa Instansi Pemerintah

4. Permen No.11 tahun 1979 tentang keselamatan kerja pada pemurnian dan Pengolahan Minyak dan Gas Bumi.

5. Internasional Labour Organization tahun 2001 6. OSHA 29 CFR 1910.119

6. Surat Dirjen Migas No.257/380/DMT/1995 tanggal 1 Maret 1995 tentang Kesepakatan Keselamatan kerja Bagi Kontraktor.

7. Sistem manajemen RU VI (ISO 9001, ISO 14001, OSHAS 18001, SMP dan MKP).

8. Pedoman Pengelolaan Keselamatan, Kesehatan Kerja dan Lindungan Lingkungan Kontrktor BP Migas No. Kpts-13/BP00000/2006-S8 dan perubahannya

9. Pedoman Manajemen Pengadaan Barang/Jasa berdasarkan Surt Keputusan No. Kpts-51/C00000/2010-S0 Rev. 02 dan/atau perubahannya.

10. Pedoman CSMS HSSE Corporate No. A002/I00200/2011-S0 Rev.2. 12. Pedoman CSMS No. A001/K00100/2015-S0 Rev.3.

\section{Kesimpulan}

PT. Pertamina Refinery Unit VI Balongan merupakan salah satu unit yang mempunyai fungsi sebagai operasi kilang diantaranya mengolah minyak dan gas bumi menjadi produk BBM (Bahan Bakar Minyak), Non BBM, dan Petrokimia. Kemudian perusahaan tersebut memiliki dua lokasi kilang, yaitu kilang balongan dan kilang produksi LPG Mundu (LPM) dengan wilayah operasi di Balongan, Mundu, dan Salam Darma.

Penerapan aspek health, safety, and environment (HSE) sendiri, PT.Pertamina Refinery Unit VI Balongan telah mengimplementasikan Contractor Safety Management System (CSMS). Penerapan Contractor Safety Management System (CSMS) tersebut paling tidak dapat mengurangi tingkat kecelakaan di perusahaan PT.Pertamina Refinery Unit VI Balongan. Hal mana ini menjadi salah satu unsur dalam sistem manajemen K3 yang biasa dikenal dengan siklus Plan-Do-Check-Action yang merupakan proses perencanaan, penerapan, pengukuran, serta pengelolaan kontraktor melalui Contractor Safety Management System (CSMS) menjadi jembatan antara Occupational Health and Safety Management System di perusahaan PT.Pertamina Refinery Unit VI Balongan.

Dimana Implementasi CSMS oleh PT.Pertamina Refinery Unit VI Balongan mengacu pada Pedoman CSMS No.A-001/K00100/2015-S9 Revisi Ke-03, Surat Keputusan Direksi No.Kpts-051/ C00000/2010-S0 Rev. 02 tentang Sistem dan Tata Kerja Pengadaan Barang / Jasa, kemudian Permenaker Nomor 5 Tahun 1996 Tentang Perencanaan SMK3 serta Peraturan Pemerintah Nomor 50 Tahun 2012 Penerapan Sistem Manajemen Keselamatan dan Kesehatan Kerja sebagai dasar hukum yang wajib di laksanakan. 
Penerapan Constractor Safety Management System (CSMS) dan Dasar Hukumnya di PT. Pertamina Refinery Unit vi Balongan

\section{Bibliografi}

A’yun, Wildaniyah Mufidatul. (2020). Urgensi Peranan Wanita dalam Perkembangan Ekonomi Syariah di Indonesia. Al-Huquq: Journal of Indonesian Islamic Economic Law, 2(2), 193-207. https://doi.org/10.19105/alhuquq.v2i2.2806

Falenshina, Nizhenifa. (2012). Implementasi Contractor Safety Management System (CSMS) Terhadap Kontraktor Project TA Unit CD III PT. Pertamina RU III Palembang.

ILO. (2011). Hari Keselamatan dan Kesehatan se-Dunia: Mencegah kecelakaan kerja melalui pelaksanaan manajemen risiko $\mathrm{K} 3$.

Mardiah, Ainal. (2017). Tinjauan pelaksanaan contractor safety management system (csms)terhadap kontraktor pada pembangunan tanki timbun di terminal bbm medan group pt. Pertamina (PERSERO) TAHUN 2016. SKRIPSI.

Moleong, Johannes. (2009). Lexy. Metodologi Penelitian Kualitatif, 107-108.

Nugroho, May Dwinantono Setyo. (2011). Gambaran Umum Tentang Peneraapan Contractor Safety Management System (CSMS) Di PT. Pertamina (PERSERO) Refinery Unit IV Cilacap.

Ramli, Samsul. (2013). Bacaan Wajib Para Praktisi Pengadaan Barang/Jasa Pemerintah. Visimedia.

Suma'mur, P. K. (1981). Keselamatan kerja dan pencegahan kecelakaan. Gunung Agung.

Suryanto. (2013). Setiap hari 9 meninggal karena kecelakaan kerja.

Yuliani, Novi, Ekawati, \& Kurniawan, Bina. (2015). Keselamatan dan Kesehatan Kerja Berdasarkan PP No . 50 Tahun 2012 di PT Angkasa Pura II ( Persero ) Bandung. Jurnal Kesehatan Masyarakat (e-Journal), 3(3), 545-554. 